\title{
The Swedish childhood diabetes study
}

\section{Vaccinations and infections as risk determinants for diabetes in childhood}

\author{
L. Blom ${ }^{1}$, L. Nyström ${ }^{2}$ and G. Dahlquist ${ }^{1}$ \\ ' Department of Paediatrics, Karolinska Institute, Sachs' Children's Hospital, Stockholm \\ ${ }^{2}$ Department of Epidemiology and Health Care Research, University of Umeå, Umeå, Sweden
}

\begin{abstract}
Summary. In a nationwide incident case referent study we have evaluated vaccinations, early and recent infections and the use of medicines as possible risk determinants for Type 1 (insulin-dependent) diabetes mellitus in childhood. A total of 339 recently onset diabetic and 528 referent children, age 0-14 years, were included. Information about infections was collected from a mailed questionnaire and about vaccinations from childhood health care centres and schools. When vaccinations were considered as possible risk factors for diabetes, a significant decrease in relative risk estimated as odds ratio (OR) was noted for measles vaccination ( $\mathrm{OR}=0.69 ; 95 \%$ confidence limits $0.48-0.98$ ). For vaccination against tuberculosis, smallpox, tetanus, whooping cough, rubella and mumps no significant effect on OR for diabetes was found. The odds ratios for Type 1 diabetes for
\end{abstract}

children exposed to $0,1-2$ or over 2 infections during the last year before diagnosis of diabetes revealed a linear increase $(\mathrm{OR}=1.0,1.96$ and 2.55 for $0,1-2$ and over 2 infections, respectively). The trend was still significant when standardized for possible confounders such as age and sex of the children, maternal age and education and intake of antibiotics and analgetics. In conclusion, a protective effect of measles vaccination for Type 1 diabetes in childhood is indicated as well as a possible causal relationship between the onset of the disease and the total load of recent infections.

Key words: Type 1 (insulin-dependent) diabetes mellitus, childhood, medicines, infectious disease, vaccinations, epidemiology.
Involvement of viruses in the aetiological process of Type 1 (insulin-dependent) diabetes has been suggested for about a century [1]. The strongest support for virus-induced diabetes is found in animal experimental models. Studies using the encephalomyocarditis (EMC) virus imply both different diabetogenic properties in closely related variants of a certain virus, and also a critical importance of the genetically associated susceptibility of the host organism $[2,3]$.

The evidence of viruses being a substantial aetiological factor for diabetes in man is less conclusive. The most compelling evidence is derived from an Australian study [4] showing that $20 \%$ of individuals with a congenital rubella syndrome had developed Type 1 diabetes at 10-year follow-up.

In 1969 Gamble et al. reported an association between Coxsackie B 4 virus and Type 1 diabetes [5], and 10 years later a Coxsackie virus was isolated from the pancreas of a child who died at diagnosis of diabetes [6]. These findings have aroused great interest and research activity, and at present there are several studies reporting elevated antibody titre in recent onset of Type 1 diabetic patients com- pared to control subjects [7,8], whereas other studies have demonstrated no such difference [9-11].

Case reports [1], epidemiological [12] and experimental cytological [13] studies have indicated an association between mumps infection in man and development of diabetes.

The possible association between viral diseases and diabetes has also prompted an interest in vaccinations as possible risk factors for diabetes [14]. An association between mumps infection and vaccination and a later elevated islet cell antibody titre and the development of Type 1 diabetes has been suggested but recent studies seem to contradict a strong relationship between the vaccination and the later development of diabetes $[15,16]$.

Population-based epidemiological evidence for an association between vaccinations and infectious disease and onset of Type 1 diabetes is, however, lacking. Therefore, a nationwide incident case-referent design has been used in the present study to answer the following questions:

- Will individual infections or combinations of infections affect the risk of developing diabetes in childhood? 
Table 1. General vaccination programme (GVP) for children in Sweden during recent decades

\begin{tabular}{|c|c|c|c|}
\hline Type of vaccination & Target group & Age group & Comments \\
\hline Tuberculosis & High risk individuals & All age groups & $\begin{array}{l}\text { Till } 1975 \text { part of GVP, later offered } \\
\text { to high risk individuals }\end{array}$ \\
\hline $\begin{array}{l}\text { "Triple"-vaccination i.e. combination } \\
\text { tetanus, diph theria, whooping cough }\end{array}$ & Earlier included in GVP & $3,4.5$ and 6 months & Finished in 1979 \\
\hline Tetanus & Included in GVP & 10-11 years & \\
\hline Measles & Voluntary & From 18 months & Introduced in 1971 \\
\hline Rubella & Included in GVP to girls & $12-13$ years & Introduced in 1974 \\
\hline $\begin{array}{l}\text { "MPR"-vaccination i.e. combination } \\
\text { measles mumps, rubella }\end{array}$ & Included in GVP & 18 months, 12 years & Introduced in 1982 \\
\hline
\end{tabular}

- Will vaccinations affect the risk of developing diabetes in childhood?

\section{Subjects and methods}

The study was approved by the Karolinska Institute Ethics Committee and the Swedish Data Inspection Board.

In the Swedish health care system all 0-14 year old children with suspected diabetes are referred to the Paediatric Departments. Allincident cases of Type 1 diabetes aged 0-14 years are reported to the Swedish Childhood Diabetes Register [17], which has close to $100 \%$ ascertainment [18]. Based on this register an incident case referent study was performed from 1 September, 1985 to 31 August, 1986, covering all reported incident cases of diabetes, in the 0-14 year age group. For each diabetic child two age-, sex-, and county-matched referent children were traced by the official Swedish population register. Questionnaires were sent simultaneously to the diabetic child and the two referent children about four weeks after the diagnosis of the disease. The collection of data by mailed questionnaires has recently been described in detail [19]. It is important to note that the focus on diabetes was not specifically mentioned in the cover letter to the questionnaire but rather that the purpose of the study was to reveal possible relationships between different childhood diseases and environmental factors. The parents of $86 \%$ of the diabetic children ( 339 of 393 ) and $67 \%$ (528 of 786 ) of the referent children returned the questionnaires. The questionnaires were thus returned by the parents of 179 diabetic boys and 160 diabetic girls and 283 referent boys and 245 referent girls. There were nosystematic differences in the diabetic or referent children whose questionnaires were returned compared to those whose were not returned as regards sex, age and county.

The families were asked if the children had suffered from a number of specified respiratory infections, common infectious diseases during childhood and other infections during their first year of life and during the year preceding the present study i. e., the last year preceding the diagnosis of diabetes in the diabetic children. Since it is conceivable that the combined effect of qualitatively different infections may influence the risk of developing Type 1 diabetes, the number of the different infections was used as a possible risk factor for diabetes in childhood. Zero infections was used as the referent level, 1-2 as first exposedlevel and $>2$ infections as second exposed level, corresponding to the frequency of $<25$ th centile, between the 25 th and 75 th centile and $>75$ th centile of frequency of infections for all the subjects.
The families also reported the type and time of vaccinations of their children. In $88.5 \%$ of the diabetic and in $82.1 \%$ of the referent children it was possible to obtain records of vaccinations from the local child health care centres and school health units. Since these records are considered the more reliable of the two available sources of information concerning vaccinations, the estimations presented are based on these records. To validate questionnaire data the responses from the questionnaires concerning vaccinations are compared to the records from the childhood care centres and schools. The Swedish official vaccination programme during the last decades is summarized in Table 1.

\section{Statistical analysis}

To avoid loss of information during analysis, the matching was dissolved since the ratio between the relative risk from matched to unmatched data was close to 1 [20]. To compare proportions chi-square tests were used. Relative risks as odds ratios and $95 \%$ confidence intervals were calculated according to Miettinen [21]. To control for possible confounders, standardized risk ratios (SRR) and $95 \%$ confidence intervals were calculated. A possible trend in dose-response was analysed using the Mantel-Haenszel extension test and a chisquare test was used for homogeneity in trend between strata. The validity of vaccination data was estimated by comparison of proportions [22] of differing responses in questionnaires vs records in diabetic and referent children and also in terms of "sensitivity" and "specificity", here meaning the ability of the questionnaire method to correctly identify children who were or were not given a specific vaccination, respectively. The analyses were performed using the QUEST software developed for the Swedish Medical Research Council by L. Gustafsson, University of Umeå, Sweden.

\section{Results}

\section{Infections during the past year and the first year of life}

As demonstrated in Figure 1 respiratory tract infections during the past year were reported more frequently in the diabetic than in referent children, the difference being statistically significant for common "bad cold" $\left(\chi^{2}=5.94\right.$; 


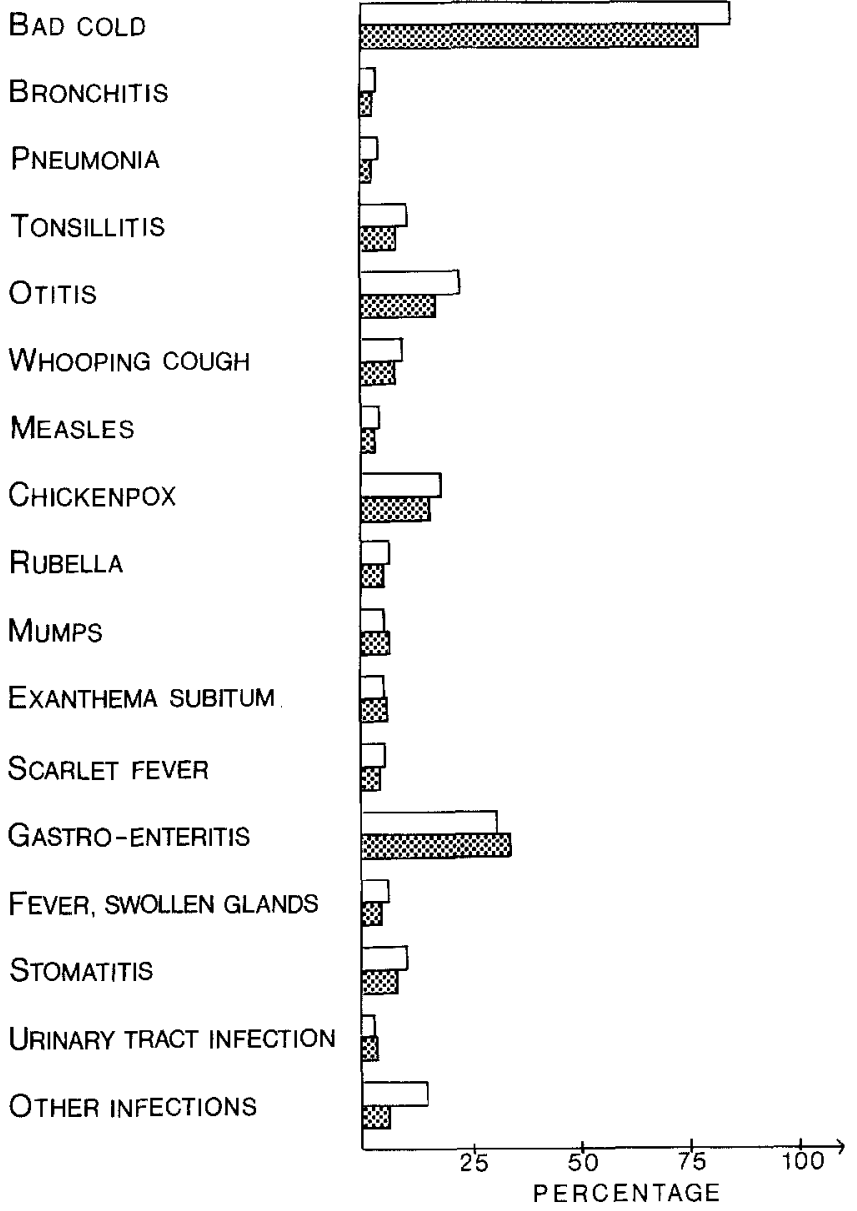

Fig. 1. Infections during the last year preceding the present study. Percentage of affected diabetic $\square$ and referent $\rightarrow$ children

$p=0.01)$ and otitis $\left(\chi^{2}=3.68 ; p=0.05\right)$. The proportion reporting common infectious diseases during childhood and other infections with specified symptoms were similar in both groups, but there was a significantly higher proportion "other infections" reported among the diabetic children $\left(\chi^{2}=19.74 ; p=0.01\right)$. When the total number of infections during the past year were aggregated and classified into three levels of exposure and used as possible risk factors for diabetes there was a consistent and statistically significant increasing trend in OR as shown in Table 2. To control for possible confounding factors such as age, sex and indices of social status such as maternal age and edu- cation recently shown to increase the risk of childhood diabetes [23] standardization for these factors were performed. The calculated standardized rate ratios (SRR) did not affect the trends significantly and did not deviate from the crude estimates (Table 2).

For infections during the first year of life no significant difference was found, with the exception of gastroenteritis, where a somewhat lower frequency $(21.2 \%$ affected diabetic children, $29.2 \%$ affected referent children, $\chi^{2}=6.38 ; p=0.01$ ) was found among the diabetic children. None of the levels of exposure for the total load of infections during this time period revealed a significantly increased relative risk of diabetes (Table 2).

\section{Vaccinations}

The proportion of vaccinated diabetic and referent children was similar for almost all vaccinations as shown in Table 3, although the frequency of some of the vaccinations differed between the younger and older age groups of children as a result of modifications of the national vaccination programme commented on in Table 1 . When vaccinations were considered risk factors for diabetes and the OR and $95 \%$ confidence limits were calculated no significant increase in OR was noted, but a significant decrease in OR was noted for measles vaccinations. As vaccinations against measles, mumps and rubella can be given either in a combined vaccine or as separated vaccinations, the effect of combined + separate vaccination respectively was also calculated. Again the combined MPR-measles vaccinated group of children showed a statistically significant decrease in risk of Type 1 diabetes.

\section{Validity of the questionnaire information about vaccinations}

The responses in the questionnaire concerning vaccinations were validated against records from childhood health care units and schools. As can be seen in Table 4 the percentage of responses differing between the two sources of information varied, but no statistically significant difference in accuracy of responses between diabetic and referent children was found. An alternative procedure to validate the questionnaire responses was used by estimating the ability of the questionnaire to correctly identify

Table 2. Odds ratio for different levels of frequency of infectious disease during the first year of life and the year preceding the present study

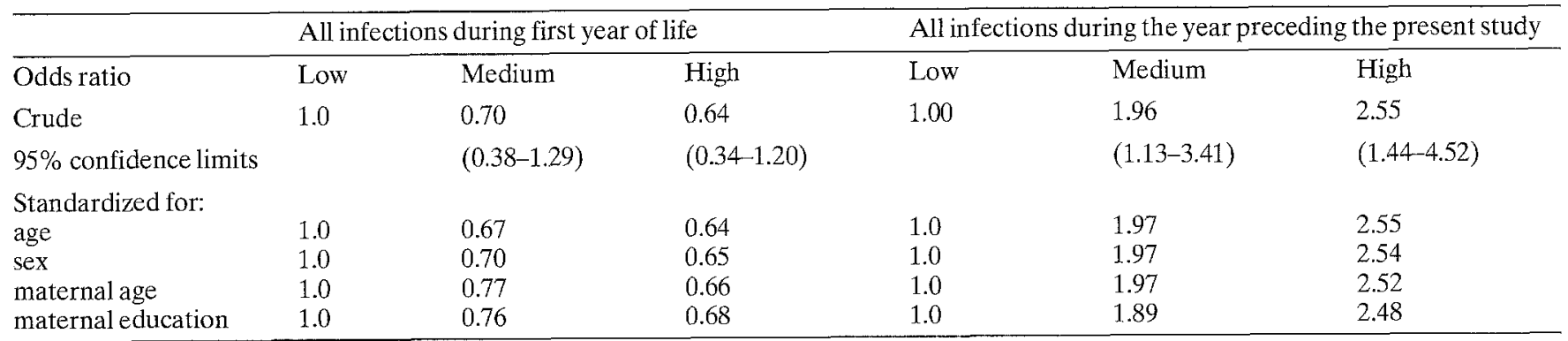


Table 3. Proportions of vaccinated diabetic and referent children. Odds ratio for Type 1 (insulin-dependent) diabetes when vaccinated

\begin{tabular}{llll}
\hline Vaccination & $\begin{array}{l}\text { Vaccinated } \\
\text { diabetic } \\
\text { children (\%) }\end{array}$ & $\begin{array}{l}\text { Vaccinated } \\
\text { referent } \\
\text { children (\%) }\end{array}$ & $\begin{array}{l}\text { Odds ratio } \\
\text { (confidence } \\
\text { limits) }\end{array}$ \\
\hline Tuberculosis & 40.3 & 39.4 & $1.04(0.77-1.40)$ \\
Smallpox & 29.1 & 27.6 & $1.07(0.77-1.49)$ \\
Triple $^{\mathrm{a}}$ & 62.0 & 63.4 & $0.94(0.70-1.28)$ \\
$\begin{array}{l}\text { Duplex } \\
\text { Tetanus }\end{array}$ & 39.3 & 40.3 & $0.96(0.71-1.30)$ \\
Polio & 33.1 & 34.1 & $0.96(0.70-1.31)$ \\
MPR $^{\mathrm{c}}$ & 99.3 & 99.3 & $1.04(0.17-6.25)$ \\
Measles & 44.0 & 45.3 & $0.95(0.71-1.28)$ \\
Mumps & 38.3 & 45.6 & $0.74(0.55-1.00)$ \\
Rubella & 2.0 & 1.2 & $1.75(0.54-5.70)$ \\
-MPR and/or & 2.0 & 1.6 & $1.24(0.41-3.73)$ \\
measles & 74.3 & 80.8 & $0.69(0.48-0.98)$ \\
MPR and/or & & & $0.95(0.70-1.27)$ \\
mumps & 44.8 & 46.2 & \\
MPR and/or & & & $0.95(0.71-1.28)$ \\
rubella & 45.0 & 46.3 & \\
\hline
\end{tabular}

a Combined vaccine diphtheria, tetanus, whooping cough; ${ }^{\mathrm{b}}$ combined vaccine diphtheria, tetanus; ${ }^{c}$ combined vaccine measles, mumps, rubella

vaccinated and unvaccinated children, respectively, in terms of sensitivity and specificity. The sensitivity varied between 0.81 and 1.0 and the specificity between 0.88 and 1.0 for the vaccinations investigated, and again no systematic difference between the two investigated groups was found.

\section{Medication}

The pattern of medication was similar for the two groups of children during the first year of life. During the last year before the present study, though, the parents reported a significantly higher use of antibiotics and analgesics, antipyretics in the diabetic than in the referent children $\left(\chi^{2}=4.37 ; p=0.03\right.$ and $\chi^{2}=3.97 ; p=0.04$, respectively) (Table 5). To investigate whether use of antibiotics or antipyretic analgesics was independently associated with the diagnosis of diabetes or just related to the frequency of infections, the OR for diabetes when exposed to different frequencies was standardized for intake of antibiotics and analgesics and vice versa. The significantly elevated OR for diabetes of a high frequency of infections remained, whereas the OR for diabetes when exposed to antibiotics and antipyretics was no longer significantly increased when standardized for frequency of infections.

\section{Discussion}

The results of the present study yield no evidence for a specific infectious agent associated with the onset of Type 1 diabetes during childhood. On the other hand, the total frequency of infectious diseases during the last year before diagnosis showed a dose-response relationship to the risk of developing Type 1 diabetes. Thus, in the present study, even if some diseases as "common cold" and otitis media tended to be increased, no specific agents were indicated. This lack of relationship could well be explained by the fact that the least detectable increased OR varies with the proportion of exposed referent subjects and the total number of subjects in the study [23]. Thus, the small number of individuals exposed to specific diseases such as mumps, measles etc yielded a low power in a study of the present size. The linear increasing trend in OR for diabetes with higher frequencies of infections may indicate a causal relationship. Alternatively, the total amount of infections may be one of the factors which precipitate the onset of the disease. The association might be explained by the well known increase in the need of insulin during infectious disease [24] rather than by specific Beta-cell damage caused by the infectious agent.

Even if the responding parents were not aware of the specific aim of the study being directed towards aetiology of Type 1 diabetes a disease dependent recall bias could be suspected to explain a different frequency of reported infectious disease between diabetic and referent children. On the other hand, no such overreporting was shown for infectious disease during the first year of life. Moreover, the validation of the questionnaire concerning information about vaccinations revealed no difference in accuracy of reporting between case and referent families. Still, the problem of disease dependent bias may exist and the results should be interpreted with caution.

The pattern of medication concerning the medicine mainly used such as antibiotics, antipyretics, analgesics and antihistamines corresponded well with the results of a recent study on drug prescription in early childhood [25]. Since the increase in crude OR for diabetes for consumers

Table 4. Comparison of information about some vaccinations in questionnaires vs records used as referent method

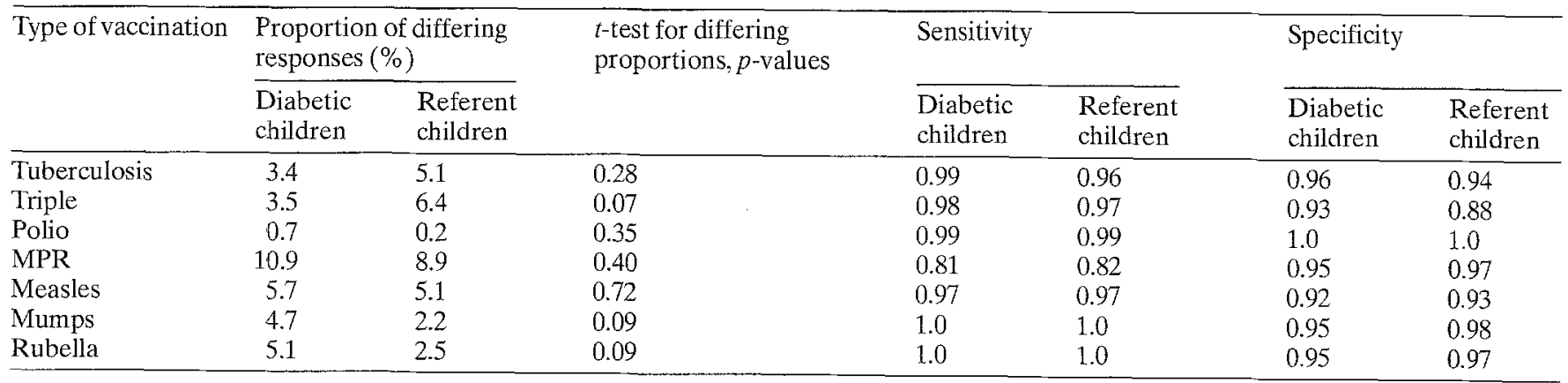


Table 5. Use of medicines during the first year of life and last year before the present study in diabetic and referent children

\begin{tabular}{|c|c|c|c|c|c|c|c|c|}
\hline \multirow[t]{3}{*}{ Types of medicine } & \multicolumn{4}{|c|}{ First year } & \multicolumn{4}{|c|}{ Last year } \\
\hline & \multicolumn{2}{|c|}{ Diabetic children } & \multicolumn{2}{|c|}{ Referent children } & \multicolumn{2}{|c|}{ Diabetic children } & \multicolumn{2}{|c|}{ Referent children } \\
\hline & $\bar{n}$ & $\%$ & $\bar{n}$ & $\%$ & $\bar{n}$ & $\%$ & $\bar{n}$ & $\%$ \\
\hline Antispasmodics & 0 & 0 & 1 & 0.2 & 1 & 0.3 & 1 & 0.2 \\
\hline Antiflatulents & 13 & 3.8 & 26 & 4.9 & 0 & 0 & 0 & 0 \\
\hline Vitamins, minerals & 2 & 0.6 & 9 & 1.7 & 1 & 0.2 & 0 & 0 \\
\hline Iron preparations & 0 & 0 & 5 & 0.9 & 0 & 0 & 0 & 0 \\
\hline Cardiovascular & 6 & 1.8 & 6 & 1.1 & 1 & 0.3 & 0 & 0 \\
\hline Ext. dermatologicals & 2 & 0.6 & 1 & 0.2 & 3 & 0.9 & 7 & 1.3 \\
\hline Corticosteroids & 0 & 0 & 0 & 0 & 2 & 0.6 & 3 & 0.6 \\
\hline Antirheumatic & 0 & 0 & 0 & 0 & 1 & 0.3 & 0 & 0 \\
\hline Analgesics, Antipyretics & 19 & 5.6 & 26 & 4.9 & $16^{\mathrm{b}}$ & $4.7^{\mathrm{b}}$ & $12^{\mathrm{b}}$ & $2.3^{\mathrm{b}}$ \\
\hline Antiepileptic & 0 & 0 & 0 & 0 & 0 & 0 & 1 & 0.2 \\
\hline Tranquilizers & 1 & 0.3 & 4 & 0.8 & 2 & 0.6 & 1 & 0.2 \\
\hline Anti-asthmatics & 13 & 3.8 & 16 & 3.0 & 24 & 9.1 & 33 & 8.5 \\
\hline Nasal decongestants & 19 & 5.6 & 36 & 6.8 & 17 & 5.0 & 24 & 4.5 \\
\hline Cough and cold preparations & 6 & 1.8 & 12 & 2.3 & 6 & 1.8 & 9 & 1.7 \\
\hline Antihistamines & 5 & 1.5 & 5 & 0.9 & 12 & 3.5 & 12 & 2.3 \\
\hline
\end{tabular}

a Onset of diabetes during first year of life; ${ }^{b}$ proportions judged to be significantly different between diabetic and referent children $(p<0.05)$

of antibiotics and analgesics during the year preceding the present study disappeared when standardized for frequency of infections, neither of these medicines were shown to increase the risk of Type 1 diabetes significantly. The greater proportion of children who later became diabetic using these medicines compared to referent children are probably due to the higher frequency of infections found in the former group.

Vaccinations have long been discussed as potential risk factors for Type 1 diabetes as they may precipitate autoimmune response towards the Beta cell [14-16]. The present findings of a significant decrease in risk of Type 1 diabetes for measles vaccinations indicate instead a protective effect. These findings were based on solid data from the child health care centres and schools and therefore would not be biased. Thus, either the measles infection could be a specific diabetogenic agent in humans or more likely the metabolic stressinduced by this relatively serious childhood disease could precipitate an early onset of Type 1 diabetes. This somewhat unexpected finding must lead to further experimental animal studies. The lack of significant effects of other vaccinations could not be interpreted unequivocally as it may be due to the close age matching and similarly good adherence to the Swedish vaccination programme of the diabetic and referent children.

In conclusion, our studies suggest,

- a high frequency of infectious disease could precipitate the onset of Type 1 diabetes in childhood,
- there was no indication that vaccinations would increase the risk of developing diabetes in childhood,

- a protective effect of measles vaccination is indicated and has to be further investigated.

Acknowledgements. The Swedish childhood diabetes study is supported by grants from the Swedish Medical Research Council, project No. B87-27X-07531-02B, the Karolinska Institute, Nordisk Insulin Foundation, the Novo Company, the Swedish Diabetes Association, the Swedish Medical Society, Svenska Diabetesstiftelsen, Stiftelsen Samariten and Förenade Liv Mutual Life Insurance Company.

\section{References}

1. Harris HF (1899) A case of diabetes mellitus quickly following mumps. Boston Med Surg J 140: 465-469

2. Craighead JE, Higgins DA (1974) Genetic influences affecting the occurrence of a diabetes-mellitus-like disease in mice infected with the encephalomyocarditis virus. J Exp Med 139: 414415

3. Yoon JW, Onodera T, Notkins AL (1977) Virus-induced diabetes mellitus VIII: passage of encephalomyocarditis virus and severity of diabetes in susceptible and resistant strains of mice. $J$ Gen Virol 37: 225-232

4. Menser MA, Forrest JM, Bransby RD (1978) Rubella infection and diabetes mellitus. Lancet I: $57-60$

5. Gamble DR, Kinsley ML, Fitzgerald MG, Bolton R, Taylor KW (1969) Viral antibodies in diabetes mellitus. Br Med J 3:627-630

6. Yoon JW, Austin M, Onodera T, Notkins AL (1979) Virus-induced diabetes mellitus. Isolation of a virus from the pancreas of a child with diabetic keto-acidosis. N Engl J Med 300: 1173-1179 
7. Gamble DR, Taylor KW, Cumming H (1973) Coxsackie viruses and diabetes mellitus. Br Med J 4:260-262

8. King ML, Shaikh A, Bidwell D, Voller A, Banatvala JE (1983) Coxsackie-B-virus-specific IgM responses in children with insulin-dependent (juvenile-onset; type 1) diabetes mellitus. Lancet I: $1397-1399$

9. Mertens T, Gruneklee D, Eggers HJ (1983) Neutralizing antibodies against Coxsackie $B$ viruses in patients with recent onset of type 1 diabetes. Eur J Pediatr 140: 293-294

10. Orchard TJ, Kuller LH, Eberhardt Met al. (1982) Approaches to the environmental etiologies of insulin dependent diabetes mellitus. In: Eschwege E (ed) Advances in diabetes epidemiology. INSERM Symposium No22. Elsevier Biomedical, Amsterdam pp 41-48

1-1. Tuvemo T, Dahlquist G, Blom L, Friman G, Landin-Olsson M, Diderholm H (1989) The Swedish childhood diabetes study III: IgM against coxsackie B viruses in newly diagnosed Type 1 (insulin-dependent) diabetic children - no evidence of increased antibody frequency. Diabetologia 32: 745-747

12. Sultz HA, Hart BA, Zielezny M, Schlesinger ER (1975) Is mumps virus an etiologic factor in juvenile diabetes mellitus? J Pediatr 86: 654-656

13. Prince GA, Jenson AB, Billups LC, Notkins AL (1978) Infection of human pancreatic beta cell cultures with mumps virus. Nature 271: $158-161$

14. Sinaniotis CA, Dackalopoulon E, Lapatsanis P, Poxiadis S (1975) Diabetes mellitus after mumps vaccination. Arch Dis Child 30: 749-750

15. Helmke K, Otten A, Willems WR et al. (1986) Islet cell antibodies and the development of diabetes mellitus in relation to mumps infection and mumps vaccination. Diabetologia 29:30 33

16. Vanndrager GJ, Molenaar JL, Bruining GJ, Plantinga AD, Ruitenberg EJ (1986) Islet cell antibodies, mumps infection and mumps vaccination. Diabetologia 29:406

17. Dahlquist G, Blom L, Holmgren G, Hägglöf B, Larsson Y, Sterky G, Wall S (1985) The epidemiology of diabetes in Swedish chil- dren 0-14 years - a six-year prospective study. Diabetologia 28: $802-808$

18. Nyström L, Dahlquist G, Rewers M, Wall S (1990) The Swedish childhood diabetes study - an analysis of the temporal variation in diabetes incidence 1978-1987. Int J Epidemiol 19: 141-146

19. Dahlquist G, Blom L, Tuvemo T, Nyström L, Sandström A, Wall S (1989) The Swedish childhood diabetes study - Results from a nine year case register and a one year case-referent study indicating that Type 1 (insulin-dependent) diabetes mellitus is associated with both Type 2 (non-insulin-dependent) diabetes mellitus and autoimmune disorders. Diabetologia 32:2-6

20. Miettinen $O$ (1972) Components of the crude risk ratio. Am J Epidemiol 96: 168-172

21. Miettinen $O(1976)$ Estimability and estimation in case-referent studies. Am J Epidemiol 103: 226-235

22. Daniel WW (1983) Hypothesis testing In: Daniel WW (ed) Biostatistics: a foundation for analysis in the health sciences. 3rd ed. Wiley \& Sons, New York Chichester Brisbane pp 192-193

23. Blom L, Dahlquist G, Nyström L, Sandström A, Wall S (1989) The Swedish childhood diabetes study - social and perinatal determinants for diabetes in childhood. Diabetologia 32: 7-13

24. Cooppan R (1985) Infection and diabetes. In : Marble A, Krall LP, Bradley RF, Christlieb AR (eds) Joslin's diabetes mellitus. Lea \& Febiger, Philadelphia, pp 737-747

25. Rasmussen F, Smedby B (1989) Life table methods applied to use of medical care and of prescription drugs in early childhood. J Epidemiol Community Health 43: 140-146

Received: 31 May 1990

and in revised form: 1 October 1990

Dr. L.Blom

Department of Paediatrics

Sachs' Children's Hospital

S-11669 Stockholm

Sweden 